\title{
O CONSUMO DE BEBIDAS ALCOÓLICAS DURANTE A PANDEMIA DO COVID-19
}

\section{Cynthia Kallás Bachur ${ }^{1,}$, Sarah Daniela Rosa Brito², Silvia Eduarda Betiati Demito² and Laurynês de Castro²}

\author{
1Fisioterapeuta, Doutora, Docente nos cursos de Fisioterapia e de Medicina da \\ Universidade de Franca. Franca - S.P. - Brasil \\ 2Estudantes do curso de Medicina da Universidade de Franca - S.P. - Brasil
}

\section{ARTICLE INFO}

\section{Article History:}

Received $11^{\text {th }}$ January, 2021

Received in revised form

$20^{\text {th }}$ February, 2021

Accepted 09 ${ }^{\text {th }}$ March, 2021

Published online $28^{\text {th }}$ April, 2021

\section{Key Words:}

Álcool, Consumo de Bebidas Alcoólicas, COVID-19, Pandemia.

\section{*Corresponding author:}

Cynthia Kallás Bachur

ABSTRACT

Com o surgimento do novo Coronavírus, as pessoas passaram a consumir álcool ainda mais em suas residências. Como agravante, tendem a usar a bebida alcoólica como ferramenta de enfrentar as mais diversas situações. Objetivo: compreender o consumo de bebida alcoólica durante a pandemia do Covid-19 e verificar a ingesta de álcool de acordo com a faixa etária.Método:Tratase de um estudo descritivo e transversal, de base populacional. Utilizou-se de dois instrumentos: sócio demográfico e o Alcohol Use Disorders Identification Test- AUDIT, composto por perguntas sobre o uso e abuso dessa substância. Resultados: Os participantes são, predominantes, da faixa etária 21-30 anos, sendo 119 do sexo feminino e 49 do sexo masculino.Esses, encontraram na bebida alcoólica um mecanismo de enfrentamento do contexto atual o que gerou uma supremacia do consumo em domićlios.O álcool foi utilizado como busca por diversão e socialização na maior parte dos casos, enquanto uma pequena parcela utiliza esse meio como fuga e medo. Conclusão: A pandemia do novo Covid-19 acarretou no aumento do consumo de bebidas alcoólicas e em uma reconfiguração dos ambientes destinados a seu uso. Observa-se uma predominância da ingesta entre os adultos em seus domicílios em busca de diversão e socialização.
\end{abstract}

Copyright (C) 2021, Cynthia Kallás Bachur et al. This is an open access article distributed under the Creative Commons Attribution License, which permits unrestricted use, distribution, and reproduction in any medium, provided the original work is properly cited.

Citation: Cynthia Kallás Bachur, Sarah Daniela Rosa Brito, Silvia Eduarda Betiati Demito and Laurynês de Castro. "O consumo de bebidas alcoólicas durante a pandemia do Covid-19”, International Journal of Development Research, 11, (04), 46372-46376.

\section{INTRODUÇÃO}

Em dezembro de 2019, em Wuhan, na China, começou a surgir casos de pneumonia, até então de causa desconhecida, porém o agente infeccioso foi o novo coronavírus. O Covid-19, faz parte da família Corona vírus (CoVs) e tem como patógeno o SARS-CoV-2, que possui efeito causador no trato respiratório, causando as mais diversas manifestações clínicas. Elas podem ser de grau variável, podendo ser até mesmo assintomáticas, as mais comuns são febre, tosse, coriza, congestão nasal e dispneia. $\mathrm{O}$ vírus acabou se espalhando rapidamente pelo o mundo, tendo a necessidade do desenvolvimento de medidas de contenção para evitar sua propagação: o uso de máscara, o distanciamento social e o fechamento de lugares considerado não essenciais (Wu et al., 2020) A maioria dos locais fechados, eram locais de reuniões sociais, em que muitas pessoas usariam o álcool e o tabaco, drogas legalizadas, como meio de diversão.
A diminuição do uso dessas substâncias nesses locais, acarretaram o aumento significativo do uso delas em domicílio, pois as pessoas tendem a buscar mecanismos de enfrentar o distanciamento social e a sua nova rotina. Muitas pessoas afirmam que o uso do álcool as ajudam a lidar melhor com os momentos de dificuldade e com o estresse (Conselho Municipal de Políticas sobre Álcool e outras drogas-COMADC, 2020). A Organização Mundial de Saúde (OMS), a par desse mecanismo, fez algumas recomendações e alertas para a população, para que assim, eles se atentem aos efeitos adversos do álcool e reduza o seu consumo. Dentre elas, podemos destacar que o álcool aumenta os sintomas de transtorno mentais, como síndrome do pânico, ansiedade e depressão, e também o risco de violência familiar e doméstica, sendo considerado uma má estratégia de enfrentamento (World Health Organization, 2020). O álcool é uma droga psicotrópica que causa depressão no sistema nervoso central (SNC) e também uma das substâncias mais usadas mundialmente, sua ação a longo prazo sobre o cérebro pode acarretar degeneração desse tecido com morte de neurônios e, assim, comprometer as funções desse 
órgão, como a memória (Costa, 2003). Estima-se que cerca de 2 milhões de pessoas faz o uso social ou o abuso dela, de acordo com dados da OMS. Um fator que leva o uso e abuso dessa substância é a influência de amizades, para se encaixar e participar de algum grupo social. Ele está interligado principalmente com as faixas etárias de crianças e adolescentes, interferindo diretamente no consumo cada vez mais precoce do álcool (Soares, 2017). Outros motivos que propiciam o consumo da bebida é a necessidade de interação com os colegas, ou como forma de distração de um problema/situações, ou alívio de tensão/stress, ou lazer, e até mesmo a expectativa em algo positivo para aumentar a confiança com outras pessoas. Percebe-se que os locais mais propícios para o uso do álcool são sua própria casa, bares, casa dos amigos e clubes (Associação Brasileira de Psiquiatria Sociedade Brasileira de Medicina da Família e Comunidade, 2012). O álcool possui efeitos a curto, médio e a longo prazo sobre o usuário. Ele interfere no funcionamento do nosso sistema imunológico, dificultando o combate viral. Pacientes que passaram pela Síndrome Respiratória Aguda Severo (SARS) durante o surto do novo Covid-19 tinham aumentado seu consumo de álcool no último ano (Jürgen Rehm Ckcfbdjmmcdhpzmsjm, 2020). Percebe-se que o álcool também pode promover prejuízo ao sistema respiratório e circulatório. É imprescindível, atentar-se que o etilista tem diminuição da capacidade dos linfócitos e de suas células de defesa, assim, estão mais propensos às doenças infecciosas. As patologias bacterianas e virais, como a pneumonia e a tuberculose, têm prevalência aumentada entre esses usuários. Infere-se que os danos causados pela bebida alcoólica são multifatoriais, dependente do estado de saúde, gênero e status socioeconômicos (Maria de Lourdes Veronezi LdFCR, 2014).

O abuso do álcool acarreta consequências muito além do que a degradação e sofrimento do usuário, mas sim, prejuízos imensuráveis. Alguns danos estão correlacionados com as perdas sociais, seja pelo afastamento de pessoas ou pelas perdas materiais decorrentes da busca incansável de suprir o vício. Outro lado afetado, é a perspectiva dos sonhos, os quais deixam de ser vislumbrados em meio aos problemas originados a partir do abuso (Lima, 2018). O usuário tende a negligenciar sua vida, tanto suas necessidades básicas como se alimentar, quanto o seu contexto interpessoal. A sua família e também seus companheiros afetivos são deixados em segundo plano, afinal, o seu amparo e prazer está sendo correlacionado com o consumo da bebida (Silva Maad, 2014). Percebe-se que a população não tem considerado os efeitos nocivos do álcool sobre o organismo e sobre sua imunidade, essencial no processo de enfrentamento contra o SARS-CoV-2. Apesar do fechamento dos locais de consumo, como bares, boates e restaurantes, por medida de proteção, nota-se o uso de domicílios como locais de aglomeração para resenhas alcoólicas (Gonçalves, 2014). Frente a isso, o objetivo deste estudo foi compreender o consumo de bebida alcoólica durante a pandemia do Covid-19 e verificar a ingesta de álcool de acordo com a faixa etária, por décadas.

\section{MÉTODOS}

Trata-se de um estudo de caráter descritivo e transversal, de base populacional, realizado no ano de 2020. A coleta dos dados foi realizada por meio de um formulário eletrônicoelaborado no Google Formsonline, onde os participantes responderam, bastando ter acesso à internet. Para o alcance dos participantes foi utilizado dados públicos, via WHATSAPP e redes sociais virtuais, por meio de compartilhamentos do link. Os participantes tiveram acesso aos instrumentos e no caso de aceite, clicaram no link "concordo", com disponibilidade primária do Termo de Consentimento Livre e Esclarecido. A população eleita para o estudo foi composta por cidadãos brasileiros, que se disponibilizaram, voluntariamente, a responder os instrumentos propostos. Sem haver distinção de gênero e raça. A amostra foi por conveniência, por meio da aceitação em participar do estudo. Como critério de inclusão, considerou-se anacionalidade brasileira, idade maior que 18 anos e menor que 60 anos. Foram excluídos aqueles que não concordarem com o Termo de
Consentimento Livre e Esclarecido e aqueles que não quiseram participar por livre escolha.

Instrumentos de coleta de dados: Os instrumentos foram aplicados por meio do envio do link, via redes sociais, junto com as informações de cunho esclarecedor. O tempo para responder os instrumentos não ultrapassa 10 minutos. Para que os dados fossem salvos, os participantes deveriam clicar em "enviar". Para caracterizar os participantes, aplicou-se um instrumento sócio demográfico com dados referentes à: idade, gênero, estado civil, escolaridade, estado de residência e ocupação. Juntamente com a informação sobre os motivos que os levaram a consumir a bebida alcoólica, como: problemas pessoais ou profissionais, ansiedade, medo, stress/tensão, diversão, socialização ou motivação pessoal (coragem). Perguntas referentes ao aumento da ingesta de bebidas alcoólicas durante a pandemia do Covid-19, bem como, os locais onde estavam sendo consumidas. Para avaliar e quantificar o consumo de bebida alcoólica durante os últimos 12 meses, aplicou-se o instrumento Alcohol Use Disorders Identification Test - AUDIT (Identificação de Problemas Relacionados ao Uso de Álcool). Considera-se dose-padrão de 14 gramas de álcool puro, em que a quantidade em $\mathrm{mL}$, varia de acordo com a bebida ingerida. $\mathrm{O}$ instrumento engloba três domínios teóricos: o consumo de bebida alcoólica- frequência, dependência do consumo de álcool e as consequências adversas desse uso. Este instrumento contém 3 domínios ( frequência, dependência e consequências negativas do consumo), totalizando10 itens a serem respondidos: $O$ primeiro está relacionado com a frequência do consumo que pode variar de 0 (nunca) a 4 (quatro vezes ou mais vezes por semana), o segundo item analisa a quantidade de bebidas alcoólicas consumida pelo participante que pode se diferenciar entre as opções 0 (não bebo),1 (1 a 2 doses), 2 ( 3 ou 4 doses), 3 ( 5 ou 6 doses), 4 ( 7 a 9 doses) e 5 (10 ou mais doses). Nas questões $3,4,5,6,7$ e 8 as alternativas variam entre: 0 (nunca) e 4 (todos os dias ou quase todos). Para os itens 9 e 10 pode-se assinala uma das três respostas: 0 (não), 2 (sim, mas não no último ano) ou 4 (sim, durante o último ano) (Méndez, 1999). Para a análise dos dados, utilizou-se do programa Microsoft Excel. As respostas dos instrumentos foram digitadas em tabelas de acordo com as faixas etárias correspondente para a interpretação dos dados obtidos. Esse trabalho foi aprovado pelo Comitê de Ética da Universidade de Franca, CAAE: 36944720.6.0000.5495.

\section{RESULTADOS}

Participaram do presente estudo 168 pessoas com faixa etária entre 18 a 60 anos, com predominância na faixa de 21 a 30 anos. A Tabela 1 apresenta a distribuição de todos os participantes, de acordo com as características sócio demográficas. A Tabela 2 apresenta a distribuição de todos os participantes de acordo com as respostas do questionário "Alcohol Use Disorders Identification Test" (AUDIT). Em relação ao aumento do consumo de bebidas alcoólicas durante a pandemia, o questionário AUDIT foi utilizado para avaliar e quantificar o consumodo álcooldurante esse momento de isolamento social. Assim, a análise do primeiro domínio (frequência de consumo) item 1,2 , e 3 demonstram que durante a pandemia a maioria das pessoas têm ingerido entre duas ou quatro vezes por mês, 39,8\% ou duas ou três vezes por semana $33,33 \%$. Percebe-se que, a maior parte dos participantes $81,54 \%$ têm ingerido menos de seis doses e mais da metade, $61,30 \%$, bebem menos de uma vez por mês 6 ou mais doses. Já no segundo domínio (dependência), item 4,5 e 6, infere-se que $76,78 \%$ dos participantes se acham capazes de controlar a bebida depois de começar, $88,09 \%$ dizem que nunca deixou de cumprir compromissos por causa da bebida e $94,64 \%$ afirmam que nunca precisou beber pela manhã para se sentir melhor, depois de ter bebido muito. Por fim, os dados do terceiro domínio (consequências negativas do consumo) itens $7,8,9$ e 10 , revelam que $1,19 \%, 2$ participantes, sentiram culpa ou remorso depois de beber e $6,54 \%$ dizem já ter prejudicado ou machucado alguém porque bebeu e que algum parente, amigo, médico ou outro profissional da saúde já se preocupou por causa da bebida ou lhe disse para parar de beber. 
Tabela 1. Distribuição absoluta e relativa dos participantes quanto às características sóciodemográficas, 2020/2021

\begin{tabular}{|c|c|c|}
\hline \multirow[t]{2}{*}{ Variáveis } & \multicolumn{2}{|c|}{ Total } \\
\hline & $\mathrm{n}$ & $\%$ \\
\hline \multicolumn{3}{|l|}{ Gênero } \\
\hline Feminino & 119 & 70,83 \\
\hline Masculino & 49 & 29,17 \\
\hline \multicolumn{3}{|l|}{ Idade } \\
\hline 18 a 20 & 24 & 14,28 \\
\hline 21 a 30 & 126 & 75 \\
\hline 31 a 40 & 12 & 7,14 \\
\hline 41 a 50 & 3 & 1,78 \\
\hline 51 a 60 & 3 & 1,78 \\
\hline$>60$ & 0 & 0 \\
\hline \multicolumn{3}{|l|}{ Estado civil } \\
\hline Solteiro & 139 & 82,73 \\
\hline Casado/ União Estável/ Mora junto com um (a) companheiro (a) & 26 & 15,47 \\
\hline Viúvo & 2 & 1,20 \\
\hline Divorciado (a) /Separado (a)/ Desquitado (a) & 1 & 0,6 \\
\hline \multicolumn{3}{|l|}{ Estado } \\
\hline $\mathrm{SP}$ & 72 & 42,85 \\
\hline MG & 71 & 42,26 \\
\hline $\mathrm{SC}$ & 7 & 4,1 \\
\hline GO & 6 & 3,57 \\
\hline MT & 4 & 2,38 \\
\hline PR & 3 & 1,78 \\
\hline $\mathrm{CE}$ & 2 & 1,19 \\
\hline $\mathrm{DF}$ & 1 & 0,59 \\
\hline MS & 1 & 0,59 \\
\hline RS & 1 & 0,59 \\
\hline \multicolumn{3}{|l|}{ Ocupação } \\
\hline Desempregado & 7 & 4,16 \\
\hline Empregado/Assalariado & 38 & 22,62 \\
\hline Profissional Liberal & 17 & 10,12 \\
\hline Empresário & 8 & 4,76 \\
\hline Estudante & 96 & 57,14 \\
\hline \multicolumn{3}{|c|}{ Quais os motivos que o levam você consumir a bebida alcoólica (1 ou mais repostas) } \\
\hline Problemas pessoais & 25 & 6 \\
\hline Problema profissionais & 9 & 2,18 \\
\hline Ansiedade & 32 & 7,78 \\
\hline Medo & 9 & 2,18 \\
\hline Estresse/Tensão & 50 & 12,16 \\
\hline Diversão & 151 & 36,73 \\
\hline Socialização & 122 & 29,68 \\
\hline Motivação Pessoal & 9 & 2,18 \\
\hline Fuga & 1 & 0,24 \\
\hline Outros & 3 & 0,73 \\
\hline \multicolumn{3}{|l|}{ Durante a pandemia do Covid-19, você: } \\
\hline Aumentou o seu consumo de bebida alcoólica & 74 & 44,04 \\
\hline Manteve o seu consumo de bebida alcoólica & 46 & 27,38 \\
\hline Diminuiu o seu consumo de bebida alcoólica & 42 & 25 \\
\hline Outros & 6 & 3,57 \\
\hline \multicolumn{3}{|l|}{ Quais os locais onde tem ingerido bebida alcoólica? (1 ou mais repostas) } \\
\hline Em sua própria casa & 132 & 41,64 \\
\hline Casa de amigos & 102 & 32,17 \\
\hline Bares/ Restaurantes / Clubes & 59 & 18,61 \\
\hline Festas & 19 & 6 \\
\hline Outros & 5 & 1,57 \\
\hline
\end{tabular}

\section{DISCUSSÃO}

Com base nos resultados desta presente pesquisa, foi possível observar que na maioria dos participantes $(44,04 \%)$ aumentaram o consumo de bebida alcoólica. Todavia, em $25 \%$ dos casos o uso do álcool diminuiu ou até mesmo se manteve $27,38 \%$. Apesar da maioria dos participantes terem aumentado a sua ingestão de bebida alcoólica, esse padrão é mutável de acordo com o modo de enfrentamento e das condições sociais de cada indivíduo. O contexto atual, trazido pelo surto do Covid-19, teve um impacto direto no comportamento social. Presentes estudos revelam que o aumento do sofrimento psicológico, provocados pelo afastamento das pessoas, dificuldades financeiras e as incertezas podem acarretar uma alteração no padrão de consumo de bebidas alcoólicas. Esse padrão pode aumentar, devido ao desgaste emocional que essa situação trouxe, ou, esse padrão pode diminuir devido a diminuição dos recursos financeiros, disponibilidade da bebida e condições físicas do próprio indivíduo (Rehm, 2020).
Diante da necessidade de enfrentamento da pandemia do novo Corona vírus foi necessário adotar novas medidas de combate não farmacológicas, sobretudo aquelas que têm em vista o distanciamento físico. O fechamento de bares, restaurantes e boates, redefiniu os lares como principal local para o consumo do álcool ${ }^{(14)}$. De acordo com o levantamento de dados, os participantes tiveram como principal local para o uso de bebidas alcoólicas sua própria casa, $41,64 \%$, e posteriormente a casa de seus amigos e familiares, $32,17 \%$. Isso demonstra ter existido uma reconfiguração no local de consumo, e que uma minoria desrespeitou a política de isolamento social e buscou locais como bares e festas para consumirem o álcool, $18 \%$ e $6 \%$ respectivamente. O álcool é uma das drogas psicoativas mais consumidas no mundo. Esse vasto consumo está interligado ao fácil acesso da substância, já que é um hábito da cultura humana há milhares de anos. Percebe-se uma precocidade no uso dessa substância sendo que o primeiro contato com a bebida é em média aos 12,5 anos (Pechansky, 2004), o que está diretamente associado a um 
Tabela 2. Distribuição absoluta e relativa das respostas referente ao "Alcohol Use Disorders Identification Test" (AUDIT)

\begin{tabular}{|c|c|c|}
\hline \multirow[t]{2}{*}{ Variáveis } & \multicolumn{2}{|c|}{ Total } \\
\hline & $\mathrm{n}$ & $\%$ \\
\hline \multicolumn{3}{|l|}{ Com que frequência consome bebidas que contêm álcool? } \\
\hline Nunca (0 pontos) & 8 & 4,76 \\
\hline Uma vez por mês ou menos (1 ponto) & 26 & 15,47 \\
\hline Duas ou quatro vezes por mês ( 2 pontos) & 67 & 39,88 \\
\hline Duas ou três vezes por semana ( 3 pontos) & 56 & 33,33 \\
\hline Quatro ou mais vezes por semanas (4 pontos) & 11 & 6,54 \\
\hline \multicolumn{3}{|c|}{ Nas ocasiões em que bebe, quantas doses, copos ou garrafas você costuma tomar? } \\
\hline Nenhuma (0 pontos) & 2 & 1,19 \\
\hline Uma ou duas ( 0 pontos $)$ & 42 & 25 \\
\hline Três ou quatro ( 1 pontos $)$ & 54 & 32,14 \\
\hline Cinco ou seis (2pontos) & 39 & 23,21 \\
\hline De sete a nove ( 3 pontos $)$ & 13 & 7,73 \\
\hline Dez ou mais (4 pontos) & 18 & 10,71 \\
\hline \multicolumn{3}{|c|}{ Com que frequência você toma seis ou mais doses em uma ocasião? } \\
\hline Nunca $(0$ pontos $)$ & 36 & 21,42 \\
\hline Menos que uma vez ao mês ( 1 ponto) & 67 & 39,88 \\
\hline Uma vez ao mês ( 2 pontos) & 34 & 20,23 \\
\hline Uma vez por semana ( 3 pontos) & 30 & 17,85 \\
\hline Todos os dias ou quase todos ( 4 pontos) & 1 & 0,59 \\
\hline \multicolumn{3}{|c|}{$\begin{array}{l}\text { Com que frequência, durante o último ano, você achou que não seria capaz de controlar a quantidade de bebida depois de } \\
\text { começar? }\end{array}$} \\
\hline Nunca (0 pontos) & 129 & 76,78 \\
\hline Menos que uma vez ao mês ( 1 ponto) & 21 & 12,50 \\
\hline Uma vez ao mês ( 2 pontos $)$ & 12 & 7,14 \\
\hline Uma vez por semana ( 3 pontos) & 4 & 2,38 \\
\hline Todos os dias ou quase todos (4 pontos) & 2 & 1,19 \\
\hline \multicolumn{3}{|c|}{ Com que frequência, durante o último ano, você não conseguiu cumprir com algum compromisso por causa da bebida? } \\
\hline Nunca $(0$ pontos $)$ & 148 & 88,09 \\
\hline Menos que uma vez ao mês (1 ponto) & 14 & 8,33 \\
\hline Uma vez ao mês (2 pontos) & 5 & 2,97 \\
\hline Uma vez por semana (3 pontos) & 1 & 0,59 \\
\hline Todos os dias ou quase todos ( 4 pontos) & 0 & 0 \\
\hline \multicolumn{3}{|c|}{$\begin{array}{l}\text { Com que frequência, durante o último ano, depois de ter bebido muito, você precisou beber pela manhã para se sentir } \\
\text { melhor? }\end{array}$} \\
\hline Nunca (0 pontos) & 159 & 94,64 \\
\hline Menos que uma vez ao mês ( 1 ponto) & 4 & 2,38 \\
\hline Uma vez ao mês (2 pontos) & 3 & 1,78 \\
\hline Uma vez por semana ( 3 pontos) & 2 & 1,19 \\
\hline Todos os dias ou quase todos ( 4 pontos) & 0 & 0 \\
\hline \multicolumn{3}{|c|}{ Com que frequência, durante o último ano, você sentiu culpa ou remorso depois de beber? } \\
\hline Nunca (0 pontos) & 82 & 48,80 \\
\hline Menos que uma vez ao mês ( 1 ponto) & 46 & 27,38 \\
\hline Uma vez ao mês ( 2 pontos) & 32 & 19,04 \\
\hline Uma vez por semana ( 3 pontos) & 6 & 3,57 \\
\hline Todos os dias ou quase todos (4 pontos) & 2 & 1,19 \\
\hline \multicolumn{3}{|c|}{$\begin{array}{l}\text { Com que frequência, durante o último ano, você não conseguiu se lembrar do que aconteceu na noite anterior por causa } \\
\text { da bebida? }\end{array}$} \\
\hline Nunca (0 pontos) & 109 & 64,88 \\
\hline Menos que uma vez ao mês ( 1 ponto) & 37 & 22,02 \\
\hline Uma vez ao mês (2 pontos) & 15 & 8,92 \\
\hline Uma vez por semana ( 3 pontos) & 5 & 2,97 \\
\hline Todos os dias ou quase todos ( 4 pontos) & 2 & 1,19 \\
\hline \multicolumn{3}{|c|}{ Alguma vez na vida você ou alguma outra pessoa já se machucou, se prejudicou porque você bebeu? } \\
\hline Não (0 pontos) & 131 & 77,97 \\
\hline Sim, mas não nos últimos 12 meses & 26 & 15,47 \\
\hline Sim, aconteceu nos últimos 12 meses & 11 & 6,54 \\
\hline \multicolumn{3}{|c|}{$\begin{array}{l}\text { Alguma vez na vida algum parente, amigo, médico ou outro profissional da saúde já se preocupou com você por causa de } \\
\text { bebida ou te disse para parar de beber? }\end{array}$} \\
\hline Não (0 pontos) & 145 & 86,30 \\
\hline Sim, mas não nos últimos 12 meses & 12 & 714 \\
\hline Sim, aconteceu nos últimos 12 meses & 11 & 6,54 \\
\hline
\end{tabular}

aumento de diagnósticos de abuso e dependência entre os jovens e adolescentes (Pechansky, 2004). Dentre as faixas etárias analisadas no presente estudo, pode-se observar que a maior participação foram pessoas entre $21-30$ anos, $75 \%$ e posteriormente entre $18-20$ anos, $14,28 \%$, o que tornou possível inferir que o álcool é um dos principais aliados dos jovens para enfrentamento de circunstâncias adversas. Sabe-se que o uso de bebida alcoólica abrange diversas faixas etárias, porém o motivo do seu consumo está associado às circunstâncias de cada indivíduo. Os motivos que levam essa ingesta estãointerligados a causas sociais e pessoais, dentre elas pode-se destacar: socialização, diversão, redução de tensão, alívio da ansiedade, stress, desconfortos pessoais, introversão e desinibição.
Os principais motivos que levam os participantes a ingerirem o álcool são a diversão, $36,73 \%$, e a socialização, $29,68 \%$. Todavia, uma pequena parcela dos participantes ainda encontra na bebida alcoólica um meio de resolução para seus medos, $2,18 \%$, e fugas, $0,73 \%$. Apartir dos resultados do instrumento AUDIT aplicado no presente estudo tornou-se possível analisar os padrões de consumo de bebida alcoólica e quantificar o número de participantes que precisariam de níveis diferenciados de intervenção profissional. Os dados obtidos indicam que a grande maioria, 98,8\%, fazem uso controlado da substância, porém 1,19\%, 2 participantes, demonstraram uso abusivo e nocivo do álcool. Isso indica que é imprescindível a conscientização 
sobre o consumo e os danos à saúde e à vida do dependente, além da necessidade de apoio profissional no resgate desses indivíduos.

\section{CONCLUSÃO}

A partir dos resultados obtidos no presente estudo, sugere-se que o consumo de álcool durante a pandemia do covid-19 aumentou, predominantes, da faixa etária 21-30 anos. A maioria dos participantes optaram por deixar os locais públicos e se restringiram ao uso domiciliar. Sabe-se que essa substância psicoativa é utilizada por diversas faixas etárias, sobretudo, foi constatado uma maior predominância entre os adultos. Nota-se que existem diversos motivos que os levam a consumir bebidas alcoólicas, porém a diversão e a socialização são os mais recorrentes. Embora essa droga seja utilizada por meios de recreação, vale lembrar que ela é causadora de uso nocivo e dependência, o que a torna uma questão de saúde pública, plausível de atenção e intervenção.

\section{REFERÊNCIAS}

Associação Brasileira de Psiquiatria Sociedade Brasileira de Medicina da Família e Comunidade. Abuso e Dependência de Álcool. Revista da Associação Médica Brasileira. 2012 Março.

Conselho Municipal de Políticas sobre Álcool e outras drogasCOMADC. O álcool e a Covid-19- orientações preventivas do conselho municipal de políticas sobre álcool e outras drogas durante a pandemia COVID-19. Cartilha de orientações. Contagem: Prefeitura; 2020.

Costa RMR. O álcool e seus efeitos no Sistema Nervoso. Monografia conclusão do curso de Biologia. Brasília: Centro Universitário de Brasília (UniCEUB); 2003.

Garcia LP, Sanchez ZM. Consumo de alcohol durante la pandemia de la COVID-19: una reflexión necesaria para enfrentar la situación. Caderno Saúde Pública. 2020 Oct 26;36.

Gonçalves, Angelica Martins de Souza MAdSSCP. Uso de álcool e/ou drogas: avaliação dos aspectos da espiritualidade e religiosos. Revista Eletrônica Saúde Mental Álcool e Drogas. 2014 Agosto; 10(2).

Jürgen Rehm Ckcfbdjmmcdhpzmsjm. Alcohol use in times of the COVID 19: Implications for monitoringand policy. Drug and Alcohol Review. 2020 Maio; 39
Kuntsche E, Knibbe R, Gmel G, Engels R. Who drinks and why? A review of socio-demographic, personality, and contextual issues behind the drinking motives in young people. Addictive Behaviors. 2006 Oct 26;31:1844-1857

Lima DWC, Ferreira LA, Vieira AN, Azevedo LDS, Silva AP, Cunha BMC, Sousa LCA. Ditos sobre o uso abusivo de álcool e outras drogas: significados e histórias de vida. SMAD. Revista Eletrônica Saúde Mental Álcool e Drogas. 2018 Sep 30;14(3):151-158.

Maria de Lourdes Veronezi LdFCR. Os efeitos biológicos da ingestão de bebidas alcoólicas. Produção Didático-pedagógica. Curitiba: Secretaria de Estado da Educação do Paraná, Superintendência de Educação; 2014. Report No.: ISBN 978-85-8015-080-3

Méndez EB. Uma versão brasileira do AUDIT. Tese de Mestrado em Epidemiologia. Pelotas: Faculdade de medicina- Universidade Federal de Pelotas, Departamento de Medicina Social; 1999

Organização da Sociedade Civil de Interesse Público (OSCIP). Álcool e a saúde dos brasileiros panorama 2019: Panorama 2019. Centro de Informações sobre Saúde e Álcool (CISA). 2019;

Pechansky F, Szobot CM, Scivoletto S. Uso de álcool entre adolescentes: conceitos, características epidemiológicas e fatores etiopatogênicos. Brazilian Journal of Psychiatry. 2004;26

Rehm J, Kilian C, Borges CF, Jernigan D, Monteiro M, Parry CDH, Sanchez ZM, Manthey J. Alcohol use in times of the COVID 19: Implications for monitoringand policy. Drug and Alcohol Review. 2020 Mar 29;39:301-304.

Silva Maad. O impacto do alcoolismo na vida social e familiar na vida do indivíduo: a intervenção do profissional de saúde de forma efetiva no tratamento. Conclusão do Curso de Especialização em Atenção Básica em Saúde da Família. Teófilo Otoni: Universidade Federal de Minas Gerais ( UFMG); 2014

Soares, Fernanda de Jesus DCOPROTSLALRAMLSSFPD. Análise dos Motivos dos Jovens e Adultos consumirem Álcool. Id on Line Revista Multidisciplinar e de Psicologia. 2017 Maio; 11.

World Health Organization. Alcohol and COVID-19: what you need to know. 2020.

Wu D, Wu T, Liu Q, Yang Z, al e. The SARS-CoV-2 outbreak: what we know. International Journal of Infectious Diseases. 2020 March: p. 44-48. 